\title{
The Modelling of Irrigation Allocation in Croatia
}

\author{
Zdravko ŠERGO, Jasmina GRŽINIĆ, Anita Silvana ILAK PERŠURIĆ
}

\begin{abstract}
Using zero-inflated Poison and negative binominal models to account for zero observations and binominal regression in the data, this study examines how irrigation patterns in Croatia vary across municipalities, with differing agricultural structures, income levels, human capital, fiscal revenues, unemployment rates, development intensities and voting profiles. The target population was irrigation adopted by farmers across Croatia and included 548 municipalities. Irrigation as a type of public good is a form of targeted economic development policy that benefits production. This research examines the following hypothesis: Do municipalities in Croatia adopt irrigation to benefit economically depressed regions and what types of agricultural structures predict the adoption of irrigation?
\end{abstract}

Keywords: count-data modelling; Croatia; irrigation; logit regression; municipalities

\section{INTRODUCTION}

The location and intensity of economic activities highly depend on the availability of water for agricultural and industrial production, sanitation and waste assimilation, transportation, and aesthetic and recreational benefits [1]. The empirical evidence suggests that economies of scale in farm production are insignificant, except in some plantation crops, as result of irrigation, and that they are more insignificant in terms of processing and marketing than in terms of production [2]. An irrigation water management system exists at different scales for both irrigation (from irrigation field to irrigation consortia) and administration (from municipality to region) [3]. In this paper, we will focus on the irrigation equipment scattered across Croatia's municipalities. This research will try to examine the following main hypothesis: Do the municipalities in Croatia adopt irrigation to benefit economically depressed regions, and what type of agricultural structure predicts this adoption? As is already known, the rapid uptake of small private irrigation in South Asia has demonstrated a positive effect on poverty alleviation [4].

The following research questions are asked in this paper in an effort to analyze the main problem: what characteristics explain and predict the probability that a municipality in Croatia utilizes an irrigation system program, and what characteristics explain the frequency with which municipalities choose to cover a particular sized area with irrigation?

The paper is organized as follows. The next section begins by mapping out the research strategy, including the conceptual framework, the dataset, the model specification and the variables. The subsequent section presents and discusses the empirical results, and the final section concludes by providing implications for economic policy and further research.

\section{CONCEPTUAL FRAMEWORK}

\subsection{Agrarian Economic Theory and Its Determinants}

Irrigation systems designate specific agrarian areas as "land zones" that qualify for irrigation equipment adoption and watering. Basic agrarian economic theory suggests that the intensified watering of land will increase the odds of transforming unfertile into more fertile land and hence increase the ability to develop select agrarian activities at the local level. In addition to allowing products with greater profit margins, the outcomes of investment in irrigation facilities can involve, for example, a guaranteed level of supply, price stability, and product quality; however, here we focus only on product selection response to the irrigation area. These products may involve opportunistic gains from vineyards and orchards, as well as from ordinary types of plantations saying vegetable gardens and nursery varieties of edible and ornamental plants instead of other less profitable crops. Some authors [5] have showed that irrigation water supplied through a collective irrigation network in the Marjeyoun region (South Lebanon) increases the area occupied by high value crops. The small family farm is often the most efficient unit of production [6]. The force of agrarian intensity acts in opposition to the force of alternative economic structures (industry, services) in a municipality. To measure the effect of agrarian intensity on the area under irrigation, we included agricultural households in the analysis. Agricultural households and land in use are adopted in this research as proxy variables for the dominant agricultural strategy of the local community.

However, this theory is built upon a number of key assumptions that are only connected to the agrarian side of the interlinked story; more complex theory that involves pure socio-economic variables at the municipality level might produce different conclusions. For example, economic considerations suggest that the propensity to adopt irrigation in a field depends on the excepted net gain in yield (revenue) from such an adoption [7]. The net gain in yield is connected to land quality and well depth, which are important factors in the choice of irrigation technology [8]. Our theoretical model, which we attempt to verify in this paper, is based on the above-mentioned orthodox agrarian economic theory augmented by specific socio-economic, political and regional factors.

\subsection{Socio-Economic Determinants}

Municipal policy choices are the product of societal actors' responses to changing economic and social conditions. Rational economic theory predicts that local state decision makers are more likely to adopt some type 
of irrigation system as a form of public good under conditions of economic duress. Assuming that the maintenance and management of an irrigation system provide a public good to rural communities, if the economic conditions in the municipality worsen, officials are more likely to respond by enacting IS (IS) as part of the infrastructure. There are increasing returns in the provision of irrigation [9]. We operationalize economic distress using the annual unemployment rate (the CDLL database, 2014). Agricultural wage and aggregate employment in the economy may also improve due to irrigation policy [10]. At too low a wage, the productivity of a worker may also be too low for the employer to be interested in hiring him. We also include an annual measure of municipality per capita income and a development index to assess whether there are any policy differences between more and less wealthy municipalities in terms of targeted agrarian development policies with an emphasis on irrigation. In wealthier municipalities, we assume that there will be less political pressure to design IS to address the need to water relatively unfertile soil. Admittedly, evidence exists in the literature that income is strongly correlated with landscaping irrigation volumes in the city of Los Angeles as well as with landscape greenness. As such, higher incomes, higher outdoor water use and greener landscapes are closely related [11]. However, in those countries in which agriculture represents an important economic activity, the greater the pressure that human activity places on water resources, the more that agriculture monopolizes available water resources, often through irrigation practices [12]. The larger the government revenue per capita and the higher on the development index, the less likely it is that a municipality will adopt an IS and increase the number of ha (hectares) under a watering regime. Governments should reduce their spending in unproductive sectors such as defence and curtail excessive subsidies in fertilizer, irrigation, power, and pesticides [13]. We include human capital in our further specification because if local decision makers are going to develop an underdeveloped region, they need a well-educated, skilled workforce to attract investment and human capital (from outside of the region). Therefore, to assess whether human capital stock positively affects the presence of an IS in a municipality, we examined the link between the adoption of IS and human capital. There is clear-cut evidence of a strong positive relationship between the schooling of a child and that child's future earnings as an adult. Schultz (1988) provides a good review of the statistical problems associated with estimating the effect of education on productivity [14]. A better education is a long-term element that contributes to an increase in income [15], and with that increase, living conditions including water supply become a priority.

\subsection{Partisanship/ldeology Determinants}

Partisan or ideological models would suggest that changes in the composition of a micro-state's political elite should lead to a change in agrarian development policy at the municipality level. Irrigation works require substantial investment [16]. Irrigation systems as part of the infrastructure in rural environments are a function of redistributive economic development policies that distribute public resources (e.g., water) from the haves to the have-nots as a rare input (for, e.g., agriculture). In fact, irrigation can be adapted to increase the efficiency of water use in agriculture. In that case, the limiting factors to such development are political commitment, policies, investments, and agronomic and management skills rather than the amount of water resources [12]. Political commitment is included within our model. Because political elites have differing views on redistributive social programs, we predict that political elites are likely to have differing views on irrigation projects based on their partisan and ideological orientations. To assess whether agrarian policy towards the construction of IS is affected by partisan or ideological factors, we include a measure of local executive partisan control and ideology based on the voting results for the Sabor (Croat parliament). We use the number of valid votes for central parliament per municipality. A "1" as a dummy variable indicates unified right-conservative control of the state government, whereas a "0" indicates unified left-liberal control of the state government. Because the supporters of IS projects over the past decade were a conservative coalition, we predict that municipalities controlled by the SDP coalition are less likely to adopt IS projects because their programs target assistance to traditionally left-wing democratic constituencies in urban areas.

\subsection{Regional Determinants}

Finally, we include a dummy variable for the three major regions to control for tradition and historical patterns in policy outcomes. However, we lack a prior theory of mutual interactions that would correlate with the dummy response variable.

\subsection{Data Set and Sources}

In this paper, secondary sources are used. The secondary data in this study are taken from various sources and refer to different variables. They cover 548 (out of 555) municipalities; seven municipalities were discarded from the sample due to incomplete data. The sampling frame of the newly created dataset is based on a list of almost all of the municipalities of Croatia. First, the data on the irrigation areas (IAs) are deduced from the Global Map of Irrigation Areas CROATIA and those data are retrieved from FAO 2013 [17]. Second, the variety of arable land use as well as data for agrarian households in Croatia are obtained from the Review of Agriculture 2003 (source: Croatian Department of Statistics). Third, we have the Croatian values for development and a calculation of the development index at the local level (henceforth, the CDLL). The CDLL is a cross-sectional, economic, nationally representative list of municipalities designed and calculated with the technical assistance of the Ministry of Regional Development and EU funds to measure microeconomic development in Croatia (2014, October 13). This dataset is retrieved from The Ministry of Regional Development and EU Funds of the Republic of Croatia [18]. Finally, the ELECTORAL database [19] covers the electoral results of Croatia's national parliamentary elections at the sub-national level. 


\section{MODEL SPECIFICATIONS}

The standard method for statistically confirming facts is to test hypotheses. In our case, we formulate the null hypothesis $\mathrm{H} 0$ that IA presence is not related to the various agricultural, socio-economic, political and regional determinants. The related, alternative hypothesis is denoted $\mathrm{H} 1$.

We use the two models to test sets of hypotheses that explain the creation and subsequent proliferation of irrigation areas.

The first model, using the presence of irrigation $(I A)$ as a dependent variable, will be estimated by logit regression:

$Y^{*}=$ const $+\sum X \beta+\varepsilon, \varepsilon \approx N(0,1)$

if $Y^{*}>0, y=1 ; Y^{*}=0, y=0$;

where $Y^{*}=I A$ presence (yes or no), $\boldsymbol{X}=$ vector of independent variable.

The estimation of a model for $I A$ size will be performed by a double-hurdle regression.

As the regression's name suggests, two hurdles must be crossed to designate a size (land plots of $I A$ in hectares, in this case). The "first hurdle" must be crossed to distribute the $I A$ by size. Because municipalities are potentially the planners of the new irrigation area, their current circumstances dictate whether they enlarge the $I A$ size and how much; this is the second hurdle.

This model is able to capture a high number of zeros [20], e.g., municipalities without irrigation design. The hurdle model assumes that all zero data referring to $I A$ are from a single "structural" source. The positive (i.e., nonzero) data have a "sampling" origin, following a truncated Poisson, truncated Geometrical or truncated negative binomial II (Negbin II) distribution (see the subchapters referring to distribution selections). For example, consider a study of IS users in which a secondary outcome is the number of tons of vegetables produced during the previous year. In this case, it is safe to assume that only non-producers will output zero tons and that all vegetable producers will score some positive (nonzero) number of tons during the last year. Hence, the zero observations can come from only one "structural" source: non-producers. If a subject is considered to be a municipality with vegetable producers, they do not have the "ability" to score zero tons of vegetables produced during the last year and will always score a positive number of tons in a hurdle model with either truncated Poisson, truncated geometrical or truncated Negbin II distributions.

The double hurdle model contains two equations that are written as follows:

$d_{i}^{*}=Z_{i}^{\prime} \alpha+u_{i}$,

$y^{*}=X_{i}^{\prime} \beta+v_{i}$.

The two error terms are assumed to be independently distributed.
The hurdle model consists of two parts (hence, it is also called a 'two-part model'). The first part is binary (given by a count distribution right-censored at $y=1$ ): is $y_{i}$ (the size of $I A$ ) equal to zero or is it positive? The second part is counted (given by a count distribution of the size variable left-truncated at $y=1$ ): if $y_{i}>0$, how large is $y_{i}$ ?

Finally, the observed variable, $y_{i}$, is determined by the interaction of both hurdles as follows:

$y=d_{i}^{*} y_{i}^{*}$

Decisions regarding whether to invest in IS and the size enlargement of area $Y$ can be jointly modelled. The questions to be answered include whether these are determined simultaneously by the decision-maker; whether these are determined separately and independently; or whether one decision is made first and affects the other sequentially (this is the dominance model, which will be used in this paper). Therefore, below we regress size on all further variables for the count part of the model and model the inflation part as a function of the same variables.

\section{EMPIRICAL METHOD AND RESULTS}

The research questions discussed earlier considered the utilization of IS programs to be a two-stage process with sequential decisions (Tab. 2 and Tab. 3). In the first stage, a decision is made by a municipality concerning whether or not to construct an irrigation facility to benefit an economically depressed community. In the second stage, another decision is made by the municipality to determine the size of the irrigation area. For both stages, the decision is affected by the factors described in the conceptual framework. However, the effects of these factors on decisions can be different at different stages. Hence, we applied a two-stage model to investigate the determinants of utilization of irrigation equipment.

In the first stage, we predicted the probability of a municipality utilizing an $I A$. Our dependent variable is binary; therefore, the probability was modelled using a binary regression. In the second stage, we predicted the frequency of IS by taking into consideration the size of these areas. Our dependent variable here is a count variable that reflects the number of ha used in irrigation adoption. In this stage, as a dependent variable rounded to an integer, we added the frequency of IS measured by the discrete size of the plot and expressed in ha.

\subsection{Variables and Descriptive Statistics}

Because this study used a two-stage model, we employed two distinct dependent variables. For the first stage, the dependent variable was whether a local government has adopted some type of irrigation infrastructure to stimulate agro-economic activity. This variable is a dummy variable that takes the value of 1 if the $I A$ concept is adopted. Conversely, it takes the value of 0 if an $I A$ does not transpire or is absent in the rural community. 
As a secondary dependent variable, we added the number of ISs in municipalities measured by size. For the second stage, the dependent variable was a size variable indicating the size of the land plots used in an irrigation enterprise for a municipality. This variable is continuous and varies from 0 to 283 ha in the first period and from 0 to 356 in the second (see the range in Tab. 1). The IS has a right-skewed data distribution, as the mean of the data values is larger than the median. The distribution of the IS shows that three-quarters of the municipalities had irrigation facilities, while a minority did not. The distribution of this variable demonstrates that the highest proportion of municipalities (approximately 37-40\%) had from 1 to 20 hectares covered by some form of irrigation during the period of observation. The second highest proportion $(25.5-26.7 \%)$ represents municipalities with very small plots (equal to or less than one ha) under the irrigation regime, while a less considerable share, approximately $5-8 \%$, had between 20 and 40 hectares irrigated. On the right side of the distribution, representing extensive irrigated areas, we have very few and sporadically distributed municipalities.

The definitions of variables and descriptive statistics are shown in Tab. 1.

Table 1 Definitions and descriptive statistics of variables used in the empirical model estimation

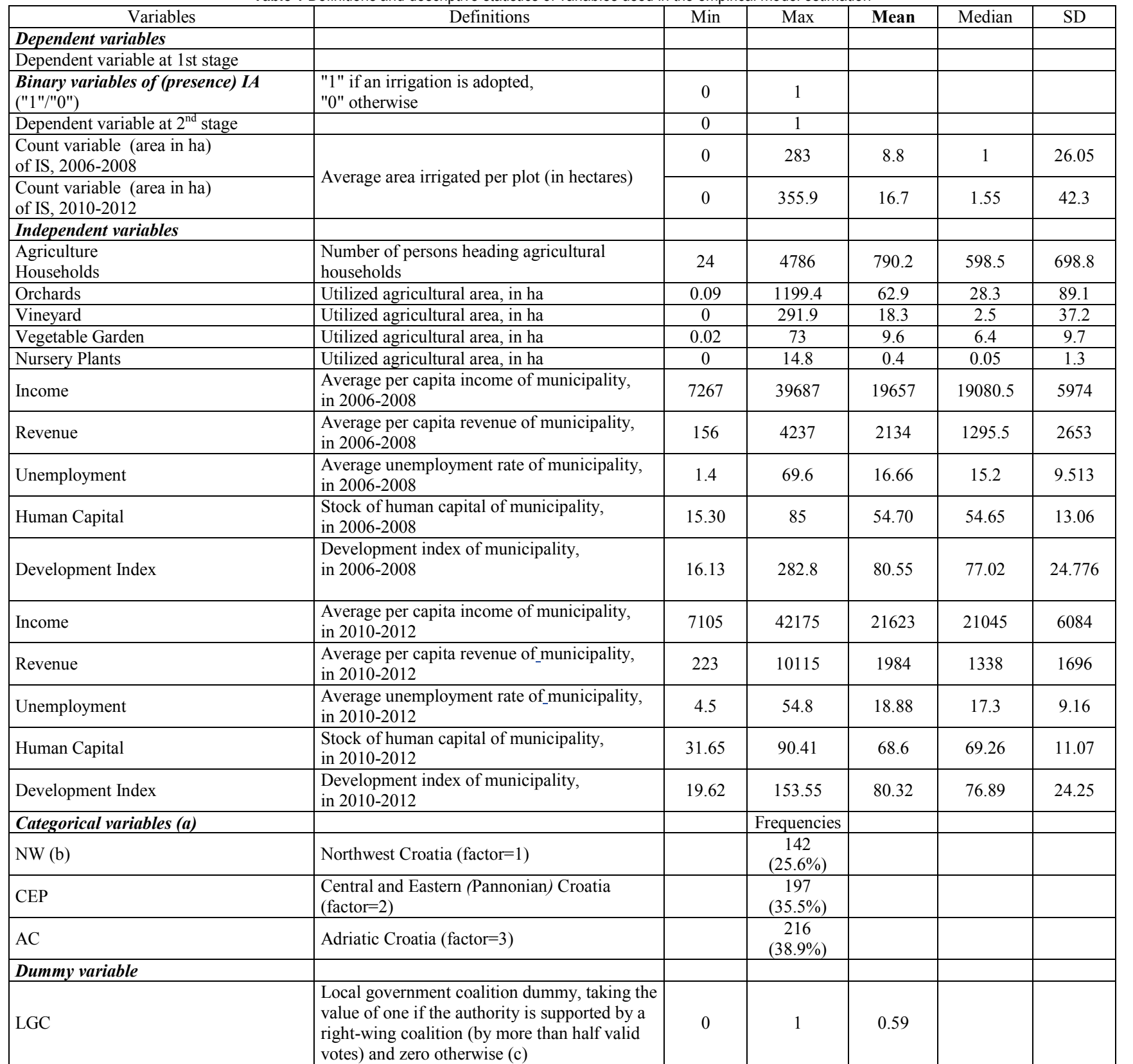

Notes: a) The frequencies with which the categories occur; b) Used as a base in the empirical model specification; c) The right-wing government in 2007 was a coalition of the following political parties: HDZ, HSS, ZS, ZDS, PGS, HSP, and HDSSB; the left-wing coalition comprised SDP, HNS, HSU-SU, and IDS party members.

The number of municipalities with a higher average IA size was greater in 2010-2012 than in 2006-2008, apparently because a higher percentage of investors participated in irrigation in the more recent period.
The typical municipality in Croatia included on average 790 agricultural households measured by the number of household heads. Tab. 1 also provides information on specific agricultural activities in need of 
irrigation facilities, namely, vegetable production from agricultural land utilization. Within arable land plots scattered across each municipality, an average of 63 hectares of orchards nurtured by farmers occupy the majority share of agricultural land per municipality; next on the list is vineyards, followed by vegetable gardens. Nurseries represent the smallest share of plantations on average (only approximately 0.05 ha).

The local communities in this paper appeared to be fairly typical in terms of the mix of rural and urban and similar to many suburban communities in Croatia with certain exceptions (see Tab. 1). Their average per capita income in 2006-2008 was approximately 19700 \$, with some of the local communities being poorer than this and one reaching approximately $39700 \$$. When compared to per capita income figures for the later period of observation, one can see that the mean income per capita is slightly lower and there is minor divergence between the poorest and wealthiest communities.
Mean per capita fiscal revenue in 2010-2012 was somewhat lower than that in 2006-2008, showing that these trends occur due to the narrowing of the tax basis and may be a negative consequence of the great recession that began in 2009 .

The average annual unemployment rate in 2006-2008 for these municipalities, at $16.66 \%$, was higher than the national average of $15 \%$, although the range of unemployment rates was rather large (1.4 to $69.6 \%)$. In 2010-2012, despite the growth in the average unemployment rate, we noted convergence between the worst and the best municipalities.

Human capital was measured using the share of the population with a high school education.

A higher share of the population with an education indicates a higher quality labour force in the local community.

\begin{tabular}{|c|c|c|c|c|c|c|c|c|}
\hline \multirow[b]{2}{*}{ Variable } & \multirow{2}{*}{$\begin{array}{c}\text { Probability of } \\
\text { having 0 IA } \\
2006-2008\end{array}$} & \multicolumn{3}{|c|}{$\begin{array}{c}\text { Probability of } \\
\text { having } 0 I A\end{array}$} & \multirow{2}{*}{$\begin{array}{c}\text { Probability } \\
\text { of } \\
\text { having } 0 I A \\
2010-2012\end{array}$} & \multicolumn{3}{|c|}{$\begin{array}{c}\text { Probability of } \\
\text { having } 0 I A\end{array}$} \\
\hline & & $\begin{array}{c}\text { Zero-hurdle } \\
\text { model, } \\
2006-2008\end{array}$ & $\begin{array}{l}\text { Exponential } \\
\text { coefficient }\end{array}$ & $\begin{array}{c}\text { Marginal } \\
\text { effect }\end{array}$ & & $\begin{array}{c}\text { Zero-hurdle } \\
\text { model, } \\
2010-2012\end{array}$ & $\begin{array}{c}\text { Exponential } \\
\text { coefficient }\end{array}$ & Marginal effect \\
\hline Constant & $\begin{array}{c}-8.026 \\
(-1.478) \\
\end{array}$ & $\begin{array}{c}-2.741 * * * \\
(-4.282) \\
\end{array}$ & 0.064 & -2.346 & $\begin{array}{l}-5.142 \\
(-0.856) \\
\end{array}$ & $\begin{array}{c}-5.745^{* *} \\
(-3.036) \\
\end{array}$ & 0.003 & -3.195 \\
\hline $\begin{array}{l}\text { Agriculture } \\
\text { Households }\end{array}$ & $\begin{array}{c}0.393 \\
(1.272) \\
\end{array}$ & & & & $\begin{array}{c}0.182 \\
(0.591) \\
\end{array}$ & & & \\
\hline Orchards & $\begin{array}{l}0.262^{*} \\
(2.103)\end{array}$ & $\begin{array}{c}0.381 * * * \\
(3.405)\end{array}$ & 1.463 & 0.105 & $\begin{array}{c}0.240 \\
(1.894) \\
\end{array}$ & $\begin{array}{c}0.344^{* *} \\
(3.090) \\
\end{array}$ & 1.411 & 0.118 \\
\hline Vineyard & $\begin{array}{c}0.142 * * * \\
(5.835)\end{array}$ & $\begin{array}{c}0.145^{* * *} \\
(6.208)\end{array}$ & 1.156 & 0.040 & $\begin{array}{c}0.142 * * * \\
(5.807)\end{array}$ & $\begin{array}{c}0.142^{* * *} \\
6.128\end{array}$ & 1.153 & 0.056 \\
\hline $\begin{array}{c}\text { Vegetable } \\
\text { Garden }\end{array}$ & $\begin{array}{c}0.595 * * \\
(2.795)\end{array}$ & $\begin{array}{c}0.793 * * * \\
(5.640)\end{array}$ & 2.211 & 0.316 & $\begin{array}{c}0.704 * * \\
(3.250)\end{array}$ & $\begin{array}{c}0.852^{* * *} \\
6.075 \\
\end{array}$ & 2.346 & 0.474 \\
\hline $\begin{array}{c}\text { Nursery } \\
\text { Plants }\end{array}$ & $\begin{array}{c}0.018 \\
(0.566) \\
\end{array}$ & & & & $\begin{array}{c}0.037 \\
(1.143) \\
\end{array}$ & & & \\
\hline Human Capital & $\begin{array}{c}0.550 \\
(0.666) \\
\end{array}$ & & & & $\begin{array}{c}-0.567 \\
(-0.481)\end{array}$ & & & \\
\hline Income & $\begin{array}{c}-1.056 \\
(-1.539)\end{array}$ & & & & $\begin{array}{c}-0.952 \\
(-1.284)\end{array}$ & & & \\
\hline Revenue & $\begin{array}{c}0.005 \\
(0.019) \\
\end{array}$ & & & & $\begin{array}{c}-0.221 \\
(-0.700) \\
\end{array}$ & & & \\
\hline Unemployment & $\begin{array}{l}0.744^{*} \\
(2.030) \\
\end{array}$ & $\begin{array}{c}0.136 \\
(0.618)\end{array}$ & & & $\begin{array}{l}0.882 . \\
(1.865)\end{array}$ & & & \\
\hline $\begin{array}{l}\text { Development } \\
\text { Index }\end{array}$ & $\begin{array}{l}2.337 \\
(1.670)\end{array}$ & & & & $\begin{array}{l}3.082 * \\
(2.295)\end{array}$ & $\begin{array}{l}0.759 \\
1.797 \\
\end{array}$ & 2.136 & 0.518 \\
\hline REGION_CEP & $\begin{array}{l}1.171^{* *} \\
(3.229)\end{array}$ & $\begin{array}{c}1.140 * * * \\
(3.520)\end{array}$ & 3.129 & 0.125 & $\begin{array}{c}1.519 * * * \\
(4.067)]\end{array}$ & $\begin{array}{c}1.215^{* * *} \\
3.742\end{array}$ & 3.373 & 0.163 \\
\hline REGION_AC & $\begin{array}{l}0.859^{*} \\
(2.480)\end{array}$ & $\begin{array}{c}0.913 * * * \\
(3.712)\end{array}$ & 2.492 & 0.093 & $\begin{array}{c}1.058 * * \\
(2.952)\end{array}$ & $\begin{array}{c}0.712 * * \\
2.722\end{array}$ & 2.038 & 0.092 \\
\hline IDEOL_RIGH & $\begin{array}{l}-0.557^{*} \\
(-1.976)\end{array}$ & $\begin{array}{l}-0.636^{*} \\
(-2.386)\end{array}$ & 0.528 & 0.023 & $\begin{array}{l}-0.575 * \\
(-2.045)\end{array}$ & $\begin{array}{l}-0.408 \\
-1.620\end{array}$ & & \\
\hline Wald $\chi^{2}$ & & 13.123 & & & & 12.976 & & \\
\hline Prob $>\chi^{2}$ & & $0.041^{*}$ & & & & $0.039 *$ & & \\
\hline $\begin{array}{l}\text { Hetero-sked. } \\
\text { LM }\end{array}$ & & $\begin{array}{l}19.266 \\
{[0.007]}\end{array}$ & & & & $\begin{array}{c}25.071 \\
{[0.0007]}\end{array}$ & & \\
\hline Log-likelihood & -275.3 & -282.5 & & & -272.6 & -281.0 & & \\
\hline AIC & 578.55 & 580.94 & & & 573.26 & 578.03 & & \\
\hline Number obs. & 548 & 548 & & & 548 & 548 & & \\
\hline
\end{tabular}

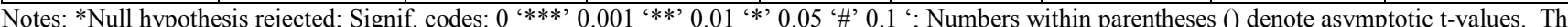
robust standard errors are applied in the Count_1 regression. The dummy variable for Region_NW, with 142 observations in sample $\approx 548$, was omitted to facilitate comparison of adoption probabilities in Region_NW with the other two regions: Region_CEP and Region_AC. The political variable IDEOL LEFT was omitted for similar reasons.

Furthermore, a higher quality labour force is expected to be more efficient; therefore, it should reduce the average cost of idleness, leading to greater entrepreneurship or other economic activities. Areas with high levels of human capital provide a solid base of employees for future agro-businesses and therefore for using IS. Hence, a positive relationship between human capital and the $I A$ variable(s) was hypothesized.

The mean values for human capital varied quite a bit between the two time-points of observation. In the later 
period, the mean value indicated that agro-entrepreneurs accessed more specialized skills.

Another measure of economic change was the change in development as measured by the development index. This overall figure decreased by small amount between the two time points, just $0.5 \%$ on average, with some of the worst communities showing an increase and the best communities showing substantial deterioration in development. Therefore, even as incomes were growing, overall economic development conditions worsened.

Three major regions (Northwest, Central and Eastern, and Coastal) were delineated to correspond with internal administrative districts and county borders. Those regions emerged from the association of Eurostat with the State Department of Statistics. The boundaries of the administrative districts overlap with those of the statistical reporting districts containing the municipalities. Following administrative boundaries and county borders, the three regions were defined by mountain ranges, river flows, lowland areas and the Adriatic Sea coast. Furthermore, these regions reflect the existing and potential economic differences across Croatia. For example, agriculture and many food industry facilities are located in the Central and Eastern region, whereas government agencies, banks, industry and other major service sector organization headquarters are located in the Northwest region. For the purpose of estimation, the Northwest region served as the base for the empirical model for the comparison of regional effects. The economy of the coastal region that stretches along the eastern part of the Adriatic Sea is mainly based on the tourism industry.

\subsection{Results of the Double Hurdle Model 4.2.1 Logit Estimations}

The results of binary estimations for the probability of adopting an $I A$ are shown in Tab. 2.

The Breusch-Pagan test outcomes provide some evidence for the presence of heteroskedasticity. Therefore, the Huber-White estimator of variance is used instead of the conventional maximum likelihood estimator of variance to avoid heteroskedasticity in both reduced regressions.

The Wald test is used to test the specific parameter constraints, i.e., the null hypothesis, which is that the omitted (insignificant) coefficients for the general model are simultaneously equal to zero. The chi-squared value generated by the Wald test is 2.187 , with an associated pvalue of 1.976 with six degrees of freedom. The $p$-value is higher than the generally used criterion of 0.05 , so we are not able to reject the null hypothesis, indicating that the coefficients are simultaneously equal to zero. Because excluding statistically insignificant predictors should lead to a better prediction (i.e., better model fit), we conclude that a reduced model will be better than a general model.

For both samples in different periods, the agrarian determinants had a significant positive coefficient in our logit regressions. The interpretation of the exponentiated coefficients of the zero-hurdle model is as follows. The baseline odds of having a positive count versus zero in the adoption of IS is 0.03 on average for both samples. These odds are increased by 1.15 times on average with a one ha unit increase in vineyards and by approximately 2.28 times on average with a one ha unit increase in vegetable gardens. Municipalities that have sown or raised plantation-type orchards in their agricultural portfolio are 1.44 times more likely to be equipped by $I A$. Thus, it appears that the co-occurrence of $I A$ and vegetable gardens in the same municipality is the most plausible event. The number of agricultural households does not have significant effect, nor does the number of nursery plantations, the level of human capital, income or fiscal potential. However, better economic development increases the odds of having $I A$ by 2.14 times in the second period, meaning that it is more likely that a municipality characterized by better economic development would adopt $I A$ in the second period. Here, the sign of the coefficient for the development index, as an independent variable in the model, was unexpected and comes as a surprise. Theoretical expectations predict the opposite: that depressed areas would be more likely to use $I A$. This counterintuitive result illuminates one of the issues regarding the use of cross-sectional data. Instead of establishing causality, effects, determinants, or impacts, our regression results may be read as implying correlations, relationships, and associations. The "correlations" presented, however, assume ceteris paribus conditions. This result indicates that better overall economic development has a strong positive impact on the likelihood of using $I A$ (with a marginal effect of $51.8 \%$ in the second observation period), which confirms that the gradual improvement of development conditions in some municipalities may help them to overcome obstacles to implementing $I A$. The calculated marginal effect tells us that the probability of increasing the development index of a municipality that adopted $I A$ was 0.518 higher than that of a municipality without $I A$, all other variables remaining the same. The positive relationship between the unemployment rate in response to the $I A$ variable agrees with our theory, but here the unemployment rate is significant at slightly less than 10 percent. The variable for Region_CEP was significant at the $0 \%$ level and positive in the Count 0 (and Count 1) equation, with a marginal effect of $12.5 \%$ (and $9.3 \%$ ). The odds of having a positive count e.g. one (of $I A$ ) versus zero compared to the benchmark Northwest region increased by 3.13 times for the Central and Eastern region. The third regional dummy for the Coastal region has a similar result, also significant at the $0 \%$ level. This indicates that, estimated in isolation, the coastal region (counties Istarska, Primorsko-Goranska, SplitskoDalmatinska and Dubrovačko-Neretvanska) was approximately 2.5 times more likely to adopt an IS relative to the average municipality in the Northwest region. Because the Central and Eastern and the Coastal regions are much more focused on agricultural development than Northwestern Croatia, this outcome is expected in the model. As for the ideological orientation of voters, we see from the negative and significant coefficient of IDEOL_RIGHT (only in the first time interval), estimated in isolation, that the more conservative units of observation were slightly less motivated to adopt $I A$ relative to the liberal areas of the sample. 


\subsubsection{Results of the Count Model Estimations for Probability}

Given that the response is positive in regard to IS adoption (among those who have positive counts), the average count is 17.76 ha in the first period (19.23 ha in the second period) of the sample observation.

A unit increase in income per capita decreases the ha under IS by 0.45 (on average) among those municipalities that have positive counts of ha under IS. The statistically significant role of income per capita in the participation and frequency decision is not puzzling given that the primary role of IS equipment should be to overcome economic depression in some areas of the country (see Tab. 3). The log of income per capita had a statistically significant and negative influence on the decision to participate in IS adoption, which was discussed earlier in this paper. This second stage of research again finds and confirms that the size plot frequency of IS as a response variable is negatively linked to the log of income per capita. According to the results, municipalities with higher income per capita were less likely to become land consumers and require irrigation than low-income per capita municipalities. These results, found in both time intervals, clearly illustrate the importance of relative poverty in determining the size of IS adoptions: higher- income populations may be less exposed to agrarian production, could live in urban areas, or may be immersed in a tradition where the strong desire to succeed leads to make land irrelevant (aside from erecting buildings). The remaining socio-economic performance variables have no significant effect at all except for the development index, which increases the plot size by 40.038 times in the first period.

The variable of agricultural intensity proxied by agricultural households (among municipalities where they lived) increase the size in ha by 2.98 times, whereas orchards increase it by slightly less than 1.27 times, both among those municipalities with positive counts (size in ha). Because agricultural intensity levels are likely to respond to growing employment opportunities within rural areas endowed with IS equipment, Tab. 3 confirms the assumed theoretical conjectures. However, these conjectures are not confirmed by the regression results when binominal model techniques are applied. The most striking result is that vineyards and plant nurseries have a significant, positive and strong impact on the probability of the IS size frequency only in the first period, while these variables are insignificant for municipalities in 2010-2012 (unlike the results from the binominal regression).

\begin{tabular}{|c|c|c|c|c|}
\hline & \multicolumn{2}{|c|}{$\begin{array}{c}\text { Count } \\
\text { (area in ha) } \\
\text { of IS, 2006-2008 }\end{array}$} & \multicolumn{2}{|c|}{$\begin{array}{c}\text { Count } \\
\text { (area in ha) } \\
\text { of IS, 2010-2012 }\end{array}$} \\
\hline & Geometric distribution & $\begin{array}{c}\text { Exponential } \\
\text { coefficient }\end{array}$ & Negbin II distribution & Exponential coefficient \\
\hline Constant & $\begin{array}{c}2.876 * * * \\
(3.333)\end{array}$ & 17.76 & $\begin{array}{c}2.956^{* *} \\
(2.964) \\
\end{array}$ & 19.23 \\
\hline Agriculture Households & $\begin{array}{c}0.883 * * * \\
(3.753)\end{array}$ & 2.418 & $\begin{array}{c}1.264 * * * \\
(3.348)\end{array}$ & 3.540 \\
\hline Orchards & $\begin{array}{l}0.167^{*} \\
(2.189)\end{array}$ & 1.182 & $\begin{array}{l}0.309^{*} \\
(2.370)\end{array}$ & 1.362 \\
\hline Vineyard & $\begin{array}{l}0.041^{*} \\
(2.241)\end{array}$ & 1.042 & $\begin{array}{c}0.037 \\
(1.360) \\
\end{array}$ & \\
\hline Vegetable Garden & $\begin{array}{c}-0.142 \\
(-0.903) \\
{[0.366]} \\
\end{array}$ & & $\begin{array}{l}-0.333 \\
(-1.292) \\
{[0.196]} \\
\end{array}$ & \\
\hline Nursery Plants & $\begin{array}{l}0.050^{*} \\
(2.410)\end{array}$ & 1.113 & $\begin{array}{c}0.027 \\
(0.798) \\
\end{array}$ & \\
\hline Human Capital & $\begin{array}{c}0.107 \\
(0.148) \\
{[0.882]}\end{array}$ & & $\begin{array}{c}0.038 \\
(0.024)\end{array}$ & \\
\hline Income & $\begin{array}{l}-3.221 * * * * \\
(-6.127)\end{array}$ & 0.039 & $\begin{array}{c}-2.98 * * * \\
(-3.481)\end{array}$ & 0.050 \\
\hline Revenue & $\begin{array}{l}-0.379 \\
(-1.890)\end{array}$ & 0.684 & $\begin{array}{c}-0.344 \\
(-0.940)\end{array}$ & \\
\hline Unemployment & $\begin{array}{c}0.553 \\
(1.793)\end{array}$ & 1.740 & $\begin{array}{c}-0.117 \\
(-0.195)\end{array}$ & \\
\hline Development Index & $\begin{array}{c}3.689 * * \\
(2.60) \\
{[0.009]}\end{array}$ & 40.038 & $\begin{array}{c}1.648 \\
(0.867) \\
{[0.385]} \\
\end{array}$ & \\
\hline REGION_CEP & $\begin{array}{c}-0.158 \\
(-0.713)\end{array}$ & 0.853 & $\begin{array}{c}1.262 * * * \\
(3.473)\end{array}$ & 3.535 \\
\hline REGION_AC & $\begin{array}{c}1.253 * * * \\
(4.901)\end{array}$ & 3.503 & $\begin{array}{l}\text { 0.999* } \\
(2.423)\end{array}$ & 2.716 \\
\hline IDEOL_RIGHT & $\begin{array}{c}-0.476 * \\
(-2.392)\end{array}$ & 0.621 & $\begin{array}{l}-0.583 \\
(-1.925)\end{array}$ & 0.557 \\
\hline
\end{tabular}

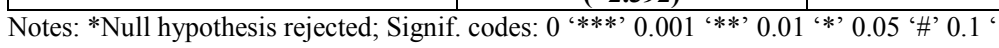

Regional differences in land plot frequencies for IS are pronounced and suggest that residents of the Adriatic region are more likely to be users of land units under an irrigation regime and, if they are users, to have more ha units under irrigation than those living in the NW region (up to 3.11 times more). The same conclusion can be reached when examining the Pannonia region (but only for the second time period). In addition, municipalities leaning more toward a right-wing ideology are less likely to include more units of ha in their IS program, and 
develop these programs more often than municipalities favouring the opposite party. That independent variable is weakly significant at the $p<0.053$ level in the second period.

\section{DISCUSSION OF THE TEST RESULTS}

Using irrigation participation and frequency data collected in Croatia for 2006-2008 and 2010-2012, this study uses binominal logit and hurdle count-data models [21] to analyze dislocated irrigation areas across municipalities in a transition economy undergoing major structural changes in that field.

We estimate three discrete single-decision and hurdle models for Poisson, geometric and negative binomial distributions to simultaneously test for over dispersion and excess zeros with regard to the number of hectares under IS. Hurdle models were shown to outperform single-decision models across the three distributions, suggesting that accounting for over dispersion and excess zeros is essential in this study. From an economic behavioural viewpoint, the results confirm that zeros and non-zeros come from two different data-generating processes. Subsequently, Vuong's non-nested model selection tests [22] identified Geometric and Negbin II hurdle models as the best fit for the 2006-2008 and 20102012 data sets, respectively, across the land plot frequencies. This indicates that accounting for unobserved heterogeneity is required in addition to addressing over dispersion and excess zeros.

One advantage of the two-stage decision model is its ability to address municipalities that reported zero frequency for land assigned to irrigation. Given the significant percentage of zero reports for most municipalities, distinguishing the decision to designate a plot of land for IS adoption is an essential component of this research.

This study provides an analysis of the agricultural determinants of municipality adoption of irrigation. Because technological change can affect the level of output, product quality, etc., the adoption of a public good such as irrigation offers economic opportunities through plant production. Broad differences were observed among the agricultural characteristics: the number of agricultural households and plant nurseries are important in the second hurdle, which predicts the number of hectares with irrigation, while these features are unimportant for the first hurdle. More specifically, the study shows important differences between the effects of vineyards and vegetable gardens on each of the two hurdles. Farmers living in municipalities cultivating plants and having access to watering are significantly more likely to adopt irrigation technology. However, once the farmer adopts irrigation, cultivation of a vineyard or a vegetable garden may not be a decisive influence on the farmer's decision to apply the irrigation in the second period.

For both samples in the different periods, the log of income per capita has a significant positive coefficient in the double-hurdle (count) models but not in the binominal models. There is a higher likelihood that a municipality with a higher standard of living will accept irrigation as a development strategy (among those that require irrigation) among those that have already anticipated irrigation as a type of public good. Poorer municipalities in Croatia, as measured by per capita income, are less likely to increase the number of hectares under irrigation to, presumably, include more economically distressed areas. It is more politically difficult to justify targeting irrigation programs for economically distressed areas in poorer municipalities when depression hits the entire national economy. As is well known, Croatia has been plagued by a recession that started in 2009. Richer municipalities are more agile in bad times and less risk averse in terms of investing in irrigation programs; thus they can deliver public goods for local agricultural households. The results of the binominal (and hurdle) regression indicate that the cumulative causation indicated by higher development index has a positive impact on the likelihood of using IS, stressing the importance of market potential for selling agricultural output among those municipalities that benefited from irrigation.

\section{CONCLUSION}

The estimated results for land (count) frequencies illustrate the importance of using the two-stage behavioural model. We did not obtain confirmation of the results from the logit regression on adoption of irrigation in the count regression. Specifically, the significant effect of unemployment on the probability of participating in irrigation demand indicates that local authorities are not driven to expand IS programs as a weapon in the battle against unemployment. Among those municipalities that use irrigation, it appears that unemployment problems are not a priority because they possess well-to-do micropopulations.

The estimated hurdle models confirm the results of the logit regressions and clearly establish that left-wing ideology directly affects the decision to adopt irrigation programs and the frequency of land in ha under irrigation. The left-wing coalition is far less represented in rural milieus. These results confirm our expectation that irrigation adoption patterns would differ across the various socioeconomic units that characterize the average municipality in Croatia. In addition, this study revealed a noticeable difference in irrigation adoption patterns across geographic regions. The economic impact of the transition towards a market economy while fighting against the fragile economies of central and eastern Pannonia and coastal Croatia is equivalent to a strong negative external shock and is further aggravating their economic situation. In 2000, the re-building of these regions often led to a lavishly subsidized agriculture sector. This region is characterized by higher initiative in IS adoption as an instrument of agricultural development than the Northwestern region. This result is consistent with an understanding that the Northwestern area is reorienting away from agriculture in the long run, and thus irrigation systems are relatively absent compared to the other two regions of Croatia.

\section{REFERENCES}

[1] Young, R. A. \& Haveman, R. H. (1985). Economics of water resources: a survey in Kneese, A. V. and Sweeney, J. L. eds. Handbook of natural resources and energy economics, 2, Amsterdam, Elsevier Science Publishers. 
[2] Binswanger, H. P., Deininger, K. \& Feder, G. (1995). Power, Distortions, Revolt, and Reform in Agricultural Land Relations. Handbook of Development Economics, eds J. Behrman and T. N. Srinivasan, 3, 2659-772. Amsterdam: North Holland. https://doi.org/10.1016/S1573-4471(05)80010-5

[3] Todorovic, M. \& Steduto, P. (2003). A GIS for irrigation management. Physics and Chemistry of the Earth, 28(4-5), 163-174. https://doi.org/10.1016/S1474-7065(03)00023-8

[4] De Fraiture, C. \& Giordano, M. (2014). Smallholder private irrigation, a thriving but overlooked sector. Agricultural Water Management, 131, 167-174. https://doi.org/10.1016/j.agwat.2013.07.005

[5] El Chami, D., Scardigno, A. \& Khadra, R. (2014). Equity for an integrated water resources management of irrigation systems in the Mediterranean: the case study of South Lebanon. New Medit: Mediterranean Journal of Economics, Agriculture and Environment, 13(4), 39-45.

[6] Bardhan, P. \& Udry, C. (1999). Development microeconomics. Oxford University Press, Oxford. https://doi.org/10.1093/0198773714.001.0001

[7] Shrestha, R. B. \& Gopalakrishnan, C. (1993). Adoption and Diffusion of Drip Irrigation Technology: An Econometric Analysis. Economic Development and Cultural Change, 41(2), pp. 407-418. https://doi.org/10.1086/452018

[8] Caswell, M. \& Zilberman, D. (1986). The Effects of Well Depth and Land Quality on the Choice of Irrigation Technology. American Journal of Agricultural Economics. 68(4), 798-811. https://doi.org/10.2307/1242126

[9] Melamed, C., Dondeynaz, C.; Carmona M. (2013). The BraSIS Project $-a$ EU-Brazil Sector Dialogue Project on Basic Sanitation. https://doi.org/10.2788/48273

[10] Sarbajit, C. \& Shigemi, Y. (2007). Formation of Special Economic Zone. Agricultural Productivity and Urban Unemployment. MPRA Paper. 5324. http://mpra.ub.unimuenchen.de/5324

[11] Caroline, M. (2013). Residential water use and landscape vegetation dynamics in Los Angeles. PhD Dissertation, University of California, Los Angeles, CA 90095.

[12] Dondeynaz, C., López Puga, J. \& Carmona, M. (2013). Bayesian networks modelling in support to cross cutting analysis of water supply and sanitation in developing countries. Hydrology and Earth System Sciences Discussion, https://doi.org/10.5194/hess-17-3397-2013

[13] Fan, S. \& White, A. (2008). Lessons learned: Major findings and policy implications. Fan, S. ed. Public Expenditures, Growth and Poverty: Lessons from developing countries, International Food Policy Research Institute. Baltimore: Johns Hopkins University Press, Chapter 7, 225-239. https://doi.org/10.1355/ae26-2k

[14] Schultz, T. P. (1988). Education Investments and Returns. In: Handbook of Development Economics. Vol. I. (Eds: Chenery, Hollis; Srinivasan, T. N.) North Holland, New York, 543-630. https://doi.org/10.4337/9781848442818

[15] Houthakker, H. S. (1959). Education and Income. The Review of Economics and Statistics, 41(1), 24-28. https://doi.org/10.2307/1925454

[16] Federico, G. (2005). Feeding the World: An Economic History of World Agriculture, 1800-2000. Princeton University Press, Princeton. https://doi.org/10.1111/j.1467-9396.2007.00663.x

[17] Croatian Department of Statistics of the United Nation, FAO 2013, http://www.fao.org/nr/water/ aquastatirrigationmap/hrv/HRV-gmia.xls

[18] The Ministry of Regional Development and EU Funds of the Republic of Croatia, http://www.mrrfeu.hr

[19] Bochsler, D. (2010). Territory and Electoral Rules in PostCommunist Democracies. Database on sub-national results of national elections in post-communist democracies, Houndmills: Palgrave. https://doi.org/10.1057/9780230281424

[20] Kleiber, C. \& Zeileis, A. (2008). Applied Econometrics with $R$. Springer-Verlag. New York. https://doi.org/10.1007/978-0-387-77318-6

[21] Winkelmann, R. (2000). Econometric Analysis of Count Data, Third edition, Berlin: Springer-Verlag. https://doi.org/10.1007/978-3-540-78389-3

[22] Vuong, Quang H. (1989). Likelihood Ratio Tests for Model Selection and non-nested Hypotheses. Econometrica, 57(2), 307-333. https://doi.org/10.2307/1912557

\section{Contact information}

Zdravko ŠERGO, PhD, Senior Research Associate Institute of Agriculture and Tourism Poreč

Karla Huguesa 8, 52440 Poreč, Croatia

E-mail: zdravko@iptpo.hr

\section{Jasmina GRŽINIĆ, Associate Professor PhD}

University Jurja Dobrile in Pula,

Faculty of Economics and Tourism "Dr. Mijo Mirković"

Preradovićeva 1/1, 52100 Pula, Croatia

E-mail: jasmina.grzinic@unipu.hr

Anita Silvana ILAK PERŠURIĆ, PhD, Senior Research Associate Institute of Agriculture and Tourism Poreč

Karla Huguesa 8, 52440 Poreč, Croatia

E-mail: anita@iptpo.hr 